\title{
PENIMBUNAN BARANG DALAM PERSPEKTIF HUKUM ISLAM
}

\author{
Afidah Wahyuni \\ Fakultas Syariah Institut Ilmu Alquran Jakarta \\ Jl. Ir. H. Juanda, Ciputat, Tangerang Selatan \\ E-mail: afidah.wahyuni@yahoo.com
}

\begin{abstract}
Abstraksi: Ihtikâr dalam perspektif hukum Islam merupakan taktik perdagangan yang sangat tidak bermoral dan juga tidak manusiawi, karena praktik perdagangan semacam itu banyak menimbulkan mudlarat bagi kehidupan manusia. Di antara madlarat yang bisa ditimbulkannya adalah kesusahan (al-dlayyiq) bagi masyarakat di dalam mendapatkan kebutuhan pangan khususnya dalam hal-hal yang bersifat dlaruri (primer). Dalam hal penimbunan barang-barang pangan yang bersifat primer dan berakibat kepada kondisi kesusahan (al-dlayyiq), bisa terjadi karena barang-barang itu secara nominal terbatas dan bisa juga karena harganya sangat tinggi sehingga tidak diragukan lagi bahwa hukumnya haram. Karena tindakan muhtakir itu mengakibatkan maslahat orang banyak terabaikan. Mengingat masalah ihtikar tersebut berkaitan dengan praktik monopoli, maka dengan sendirinya monopoli yang berakibat kesusahan (al-dhayyiq) bagi masyarakat juga haram hukumnya, karena ia merupakan penghantar dari praktik yang diharamkan hukum Islam. Untuk itu, diperlukan peran pemerintah guna menghindari praktik-praktik tidak terpuji. Bahkan di dalam menanggulangi praktik-praktik itu pemerintah berhak menentukan hukuman.
\end{abstract}

Kata Kunci: ihtikâr, ekonomi Islam, Hukum Islam

\section{Pendahuluan}

Dalam Islam, permasalahan ekonomi merupakan salah satu yang sangat fundamental bagi umat Islam. Maka dari itu, tidak sedikit umat Islam pada masa lampau yang bergelut dalam permasalahan tersebut. ${ }^{1}$ Perlu diingat

${ }^{1}$ M. Dawam Rahardjo, Ensiklopendi Al-Qur'an, (Jakarta: Paramadina, 1996), Cetakan 1. h. 575 . 
pula bahwa Islam pada sekitar empat abad (ke-8, ke-9, ke-10, ke-11) lamanya menjadi penguasa di belahan dunia ini. Hal itu bisa terjadi karena umat Islam mendapat dukungan sektor ekonomi yang sangat besar. Dalam sejarah tercatat bahwa negara Islam pada masa itu menjadi transit perdagangan internasional sebelum barang-barang dagangan diekspor ke wilayah-wilayah Eropa dan sekitarnya. ${ }^{2}$ Namun, sayangnya umat Islam pada masa-masa berikutnya malah tertindas, bahkan dijajah oleh bangsabangsa Barat. Permasalahan tersebut diduga oleh para pengamat akibat kurangnya perhatian para tokoh agama dalam masalah itu. Perhatian mereka lebih banyak terfokus kepada masalah-masalah ibadat saja. Akibatnya, dari banyak negara Islam di dunia pada umumnya tergolong negara miskin. ${ }^{3}$

Dalam rangka menggalakkan perekonomian umatnya, Islam memberikan motivasi yang sangat besar terhadap para pemeluknya. Sehubungan dengan hal itu, di dalam al-Qur'an banyak ditemukan ayat-ayat yang bertendensikan ekonomi. Kata yang bertendensikan ke arah itu antara lain di dalam al-Qur'an adalah ززق (rizki). Dawam Rahardjo di dalam bukunya Ensiklopedia al-Qur'an mencatat bahwa kata-kata eve itu disebut sebanyak 112 kali dalam 41 surat. Lokasinya yang terbanyak adalah surat al-Baqarah (12 kali), al-Nahl (9 kali), dan Saba' (7 kali). Lebih lanjut ia mengatakan 45,6 persen dari jumlah itu berbentuk kata kerja (اسم) dan sisanya berbentuk kata benda (اسم). ${ }^{4}$ Pemilahan Allah Swt ke dalam bentuk فعل dan tersebut barangkali dimaksudkan untuk memberikan dimensi aktif dan pasif dalam memperolah rizqi tersebut. Dengan kata lain, bahwasanya rizqi itu sudah disediakan oleh Allah Swt. Akan tetapi, untuk mencapainya seseorang harus bekerja keras dan tidak boleh berpangku tangan menunggu hujan rizqi.

${ }^{2}$ H.A. Mukti Ali, "Agama dan Perkembangan Ekonomi di Indonesia", Dalam Muhammad Wahyuni Nafis dkk, (Ed), Kontekstualisasi Ajaran Islam: 70 tahun Prof. Dr. Munawir Sjadzalie, M.A. (Jakarta: Paramadina, 1995), Cetakan ke-1. h. 591

${ }^{3}$ M. Dawam Rahardjo, Perspektif Deklarasi Makkah Menuju Ekonomi Islam, (Bandung: Mizan, 1987), Cetakan ke-1. h. 121

${ }^{4}$ M. Dawam Rahardjo, Ensiklopedi al-Qur'an. ., h. 578 
Dalam kaitan manusia sebagai makhluk sosial, ${ }^{5}$ umat Islam tidak bisa menghindarkan diri dari proses ekonomi global seperti pada masa sekarang ini, karena ia merupakan salah satu tolak ukur bagi kesuksesan manusia itu sendiri. Betapa banyak orang berekonomi lemah di dunia ini yang tersisa dari percaturan kehidupan, bahkan ditindas dan hampirhampir saja diperbudak oleh yang berekonomi kuat. Ini merupakan salah satu indikasi yang bisa dijadikan sandaran analisis selanjutnya bagi penyamaan peran serta umat Islam dalam bidang ekonomi. Mengingat pentingnya ekonomi di dalam kehidupan manusia, sampai-sampai Nabi Muhammad dalam suatu kesempatan bersabda,"Aku berlindung kepadaMu (ya Allah) dari (malapetaka) kufur dan kefakiran". ${ }^{6}$

Dengan demikian, dapat dipahami mengapa ekonomi sangat fundamental artinya bagi kehidupan umat Islam. Dalam ungkapan yang lebih sederhana, dapat dikatakan bahwa kefakiran dapat membawa kekufuran.

\section{Konsep Ekonomi Islam}

Sebagai mahluk sosial, manusia sangat berkepentingan dengan ekonomi, oleh karena ia merupakan penopang kehidupannya. Karena sangat interesnya manusia akan hal itu, sampai-sampai Allah Swt ketika menurunkan suatu wahyu-Nya, ia memulai dengan kalimat "tijârah".

"Apabila mereka melihat perniagaan atau permainan, mereka bubar untuk menuju kepadanya dan mereka tinggalkan kamu sedang berdiri (berkhotbah).

Katakanlah: "Apa yang di sisi Allah adalah lebih baik daripada permainan dan perniagaan”, dan Allah sebaik-baik Pemberi rizqi”(Q.s./62:11)

Kata tijârah tersebut diproyeksikan untuk menarik perhatian manusia yang secara naluriah berkecimpung dengan masalah ekonomi (perdagangan). Ini membuktikan bahwa prinsip ekonomi dalam Islam bersifat religius yang bertendensikan tauhid. ${ }^{7}$ Begitu juga sebaliknya orang yang taat beragama dan menghayati esensi ajarannya tidak akan mengabaikan aspek dunia.

${ }^{5}$ Ali Yafi, Menggagas Fikih Sosial, (Bandung: Mizan, 1994), h. 202.

${ }^{6}$ Abu Daud Sulaiman Ibn al-Asy'ari as-Sajistani al-Azdi, Sunan Abû Dâud, (Bairut: Dar al-Fikr, t.t.), Jilid II, h. 295.

${ }^{7}$ M. Dawam Raharjo, Ensiklopedi al-Qur'an..., h. 586 
"Dan carilah pada apa yang telah dianugerahkan Allah kepadamu (kebahagiaan) negeri akhirat, dan janganlah kamu melupakan bahagianmu dari (keni `matan) duniawi dan berbuat baiklah (kepada orang lain) sebagaimana Allah telah berbuat baik kepadamu, dan janganlah kamu berbuat kerusakan di (muka) bumi. Sesungguhnya Allah tidak menyukai orang-orang yang berbuat kerusakan." (Q.s/28:77)

Di dalam ayat ini tercakup aspek ekonomi. Oleh karena itu, aspek ekonomi tidak bisa dipisahkan dari tujuan untuk mencapai kehidupan akhirat karena ia merupakan pengantar bagi kehidupan itu. ${ }^{8}$ Indikasi akan hal itu dapat tercermin dari ucapan Nabi tersebut di atas bahwa antara kondisi kehidupan dunia berimplikasi kepada status keimanan seseorang.

Ekonomi Islam dikatakan bersifat religius yang bertumpu kepada tauhid, karena setiap muslim berkeyakinan bahwa rizqi yang mereka peroleh merupakan pemberian Allah Swt kepadanya melalui sunnah-Nya. Al-Qur'an juga menyebutkan bahwa setiap muslim harus berpartisipasi di dalam aktivitas ekonomi.

"Apabila telah ditunaikan sembahyang, maka bertebaranlah kamu di muka bumi; dan carilah karunia Allah dan ingatlah Allah banyak-banyak supaya kamu beruntung." (Q.s/62:10)

Dan harus bekerja keras.

"dan orang-orang yang berjalan di muka bumi mencari sebagian karunia Allah". (Q.s/73:20)

Di samping itu, disebutkan juga di dalamnya bahwa setiap muslim dijamin $^{9}$ untuk mendapatkan dari apa yang diusahakannya.

"Dan janganlah kamu iri hati terhadap apa yang dikaruniakan Allah kepada sebahagian kamu lebih banyak dari sebahagian yang lain. (Karena) bagi

${ }^{8}$ Weber mengatakan bahwa ajaran sebagian agama seperti Hidu, merupakan salah satu penghambat pengembangan ekonomi oleh karena para pengikutnya lebih mementingkan kehidupan setelah di dunia dibandingkan dengan kehidupan dunia sekarang ini. Lihat Haryati Soebadio, Bahan Kuliah Metodologi Penelitian Sosial Budaya, Pascasarjana IAIN Jakarta, Bagian II, h. 17

${ }^{9}$ Abdul Karim Zaydan, al-Fard wa al-Daulah, (Lebanon: Dâr al Qur'an al-Karim, 1978), h. $75-76$ 
orang laki-laki ada bahagian daripada apa yang mereka usahakan, dan bagi para wanita (pun) ada bahagian dari apa yang mereka usahakan, dan mohonlah kepada Allah sebagian dari karunia-Nya. Sesungguhnya Allah Maha Mengetahui segala sesuatu." (Q.s/4:32)

Namun, perlu diingat pula bahwa tidak sepenuhnya dari apa yang mereka peroleh dan mereka miliki menjadi milik seutuhnya. Hal ini terlihat dari adanya konsep infak wajib seperti zakat ${ }^{10}$ dan infak sunnah seperti sadaqah, hibah, dan lain-lain. Dengan demikian dapat dimengerti bahwasanya harta itu berfungsi sosial. ${ }^{11}$ Doktrin sosialisasi kepemilikan sangat penting artinya, karena dengan doktrin itu kondisi kesenjangan sosial $^{12}$ yang menjurus kepada perilaku distorsi dapat dihambat. ${ }^{13}$ Tidak bisa dipungkiri bahwa ketidakteraturan, distorsi dan bahkan revolusi yang terjadi pada masa-masa silam dipicu oleh masalah-masalah yang berkaitan dengan ekonomi. Akibatnya isu ekonomi itu menjadi senjata yang sangat ampuh untuk menggugat hegemoni di dunia ini. ${ }^{14}$ Untuk menghindari hal itu, perlu diciptakan suatu kondisi keseimbangan di dalam masyarakat untuk memperoleh dan mendapatkan harta kekayaan sehingga tidak terjadi konsentrasi di kalangan tertentu di dalam masyarakat. Meskipun demikian perlu diingat bahwa keseimbangan tidak dimaksudkan penyamarataan sebagaimana di dalam sistem komunis, melainkan yang dimaksud adalah agar tidak terjadi kesenjangan yang luar biasa lebarnya antara si kaya dan si miskin, di samping agar setiap individu mempunyai kesempatan yang adil untuk mendapatkannya. Oleh

${ }^{10}$ Al-Qur'an (9:34) menyatakan yang arti lengkapnya sebagai berikut, “. .. Dan orangorang yang menimbun emas dan perak dan tidak menginfakkan (sebagian) darinya di jalan Allah, maka beritahukanlah kepada mereka (bahwa mereka akan mendapatkan) siksa yang pedih".

11 Joesoef Syuyb, Masalah Zakat dan Sistem Moneter, (Medan: Rainbow, 1987), cetakan I, h. 160-161

12 Doktrin ini merupakan antipoda dari sistem kapitalis yang lebih mementingkan pengerukan dan penguasaan harta (kekayaan yang tidak terbatas bagi pemiliknya). Lihat Abu al-A'la al-Maududi, Problema-problema Ekonomi Islam dan Pemecahannya dalam Islam.., h. 37

${ }_{13}$ Muhammad Bedjaouni, Menuju Tata Ekonomi Dunia Baru, (Jakarta: Sumber Bahagia, 1985), cetakan II, h. 13-14. Lihat juga Sayid Quthb, Dasar-dasar Ekonomi Sosial dalam Kitab Tafsir fi Dzilalil Qur'an, h. 36-37

${ }^{14}$ Muhammad Bedjaouni, Menuju Tata Ekonomi..., h. 16 
sebab itu, Islam tidak menafikan persaingan di dalam ekonomi. Hal ini terlihat dari firman-Nya.

"Dan janganlah kamu iri hati terhadap apa yang dikaruniakan Allah kepada sebahagian kamu lebih banyak dari sebahagian yang lain. (Karena) bagi orang laki-laki ada bahagian daripada apa yang mereka usahakan, dan bagi para wanita (pun) ada bahagian dari apa yang mereka usahakan, dan mohonlah kepada Allah sebagian dari karunia-Nya. Sesungguhnya Allah Maha Mengetahui segala sesuatu." (Q.s/4:32)

Ayat di atas menunjukkan bahwa seseorang harus mencari harta secara wajar dan halal (usaha) meskipun dalam rangka mendapatkan hal itu harus terjadi suatu persaingan. Namun persaingan yang dilakukan adalah yang wajar pula. Usaha mencari harta seperti itu merupakan sebaik-baik cara bagi seorang muslim sebagaimana sabda Nabi. ${ }^{15}$ "Tidak seorangpun makan sesuatu yang lebih baik dari hasil kerja tangannya, dan sesungguhnya Nabi Allah Daud makan dari hasil kerja tangannya."

Dengan demikian, tidak ada jalan lain bagi seorang muslim untuk mendapatkan harta kekayaan selain harus berusaha, bekerja keras, karena ia merupakan cara yang halal baginya untuk mendapatkan harta (rizq).

\section{Ekonomi dan Keuntungan}

Merupakan suatu keharusan di dalam proses ekonomi apabila para pelakunya menginginkan keuntungan. Hanya saja keuntungan yang ingin diperoleh hendaknya tidak bertendensikan eksploitasi dan ketidakwajaran. Untuk menghindari hal itu Allah Swt menurunkan ayat alQur'an.

"Orang-orang yang makan (mengambil) riba tidak dapat berdiri melainkan seperti berdirinya orang yang kemasukan syaitan lantaran (tekanan) penyakit gila. Keadaan mereka yang demikian itu, adalah disebabkan mereka berkata (berpendapat), sesungguhnya jual beli itu sama dengan riba, padahal Allah telah menghalalkan jual beli dan mengharamkan riba. Orang-orang yang

${ }^{15}$ Abû 'Abd Allâh Muhammad Ibn Ismâil Ibn Ibrahim Ibn al-Mu'asyarah Ibn Birdazbah al-Bukhari al-Ja'fa, Sahih al Bukhari, (Kairo: Mathabi'uay Sya'bi, t.t.), h. 67 
telah sampai kepadanya larangan dari Tuhannya, lalu terus berhenti (dari mengambil riba), maka baginya apa yang telah diambilnya dahulu (sebelum datang larangan); dan urusannya (terserah) kepada Allah. Orang yang mengulangi (mengambil riba), maka orang itu adalah penghuni-penghuni neraka; mereka kekal di dalamnya" (Q.S. 2:75).

Ayat di atas menerangkan bahwa"Allah Swt menghalalkan jual beli dan mengahramkan riba". Dengan kata lain, firman-Nya menegaskan bahwa praktek mencari keuntungan melalui jalan riba tidaklah sama dengan mencari keuntungan dengan cara yang wajar, yaitu jual beli. Oleh sebab itu, cara riba dan cara jual beli sama sekali berbeda. Di samping itu, juga dapat dipahami bahwa ayat tersebut menunjukkan bahwa manusia selaku makhluk sosial, ia tidak berdiri sendiri di dalam memenuhi kebutuhan hidupnya. Untuk itulah berlaku proses perdagangan di antara sesamanya agar satu sama lain saling melengkapi.

Islam tidak membenarkan praktik di dalam mencari keuntungan seperti apa yang terjadi di dalam sistem kapitalis. Yaitu, suatu sistem yang membenarkan segala cara untuk mendapatkan keuntungan yang besar termasuk di dalamnya bentuk monopoli dan penimbunan barang dagangan $^{16}$ yang kesemuanya itu akan menimbulkan kepincangan ekonomi di dalam masyarakat pada umumnya dan pelaku ekonomi itu sendiri pada khususnya. Oleh karena itu, pelaku ekonomi hanya diperkenankan mengambil keuntungan yang baik dan wajar, tidak terlalu tinggi yang akan berakibat kepada kesusahan masyarakat, dan juga tidak terlalu rendah yang akan berakibat kepada kebangkrutannya.

Dapat dipahami bahwa, untuk menghindari praktik-praktik ekonomi yang tidak wajar seperti pengerukan keuntungan yang berlebihan maka diperlukan partisipasi semua pihak dalam ekonomi. Oleh sebab itu, tidak dibenarkan penguasaan barang dagangan di satu tangan agar hal semacam itu tidak terjadi.

${ }^{16}$ Abû al-A'lâ al-Maududi, Problema-problema Ekonomi Islam dan Pemecahannya dalam Islam. ., h. 37 


\section{Ihtikâr dalam Sorotan Hukum Islam}

Penimbunan barang ${ }^{17}$ atau di dalam bahasa Arabnya dikenal ihtikâr, merupakan salah satu problem ekonomi cukup serius tidak terkecuali Islam yang secara normatif telah memprediksikan hal itu, tetapi juga non-Islam. Sebelum membicarakan hal itu lebih lanjut, ada baiknya apabila diadakan perenungan kembali terhadap kandungan Surat Yusuf mulai ayat 46 sampai dengan 48 berikut:

"(Setelah pelayan itu berjumpa dengan Yusuf dia berseru): "Yusuf, hai orang yang amat dipercaya, terangkanlah kepada kami tentang tujuh ekor sapi betina yang gemuk-gemuk yang dimakan oleh tujuh ekor sapi betina yang kuruskurus dan tujuh bulir (gandum) yang hijau dan (tujuh) lainnya yang kering agar aku kembali kepada orang-orang itu, agar mereka mengetahuinya." Yusuf berkata: "Supaya kamu bertanam tujuh tahun (lamanya) sebagaimana biasa; maka apa yang kamu tuai hendaklah kamu biarkan dibulirnya kecuali sedikit untuk kamu makan. Kemudian sesudah itu akan datang tujuh tahun yang amat sulit, yang menghabiskan apa yang kamu simpan untuk menghadapinya (tahun sulit), kecuali sedikit dari (bibit gandum) yang kamu simpan."

Kandungan Ayat-ayat di atas menunjukkan betapa Nabi Yusuf ${ }^{18}$ sangat prihatin terhadap apa yang akan menimpa orang-orang Mesir apabila mereka tidak segera mengambil tindakan preventif guna mencegah musibah itu. Oleh sebab itu, ia menganjurkan mereka untuk menanam gandum sebanyak-banyaknya dan menyisihkan sebagian besar darinya untuk dijadikan sebagai cadangan pangan nasional. Tindakan itu sangat tepat menurut persepsi Nabi Yusuf agar nestapa akibat paceklik yang akan menimpa mereka dapat dihindari.

Namun demikian, perlu dikaji lebih lanjut apakah tindakan Nabi Yusuf tersebut relevan dengan pembicaraan ihtikâr di dalam makalah ini atau tidak. Terlepas dari apakah hal itu relevan atau tidak, yang jelas banyak hadits Nabi yang berkaitan dengan masalah ihtikâr. Sebelum

${ }^{17}$ Berasal dari akar kata al-hukrah yang berarti mengumpulkan sesuatu dan menahannya untuk menunggu harga yang tinggi. Lihat al-Munjid, h. 146

${ }^{18}$ Pertimbangan Yusuf tersebut berdasarkan permintaan Raja Mesir al-Rayyah alWahid (perdana menterinya bernama Al-Aziz) untuk mentakwilkan mimpinya. Lihat alSyawkâni di dalam Fath al- Qadîr, h. 30-31 
membicarakan perihal masalah itu secara lebih mendetail dan korelasinya dengan kebijakan Nabi Yusuf, perlu diperhatikan terlebih dahulu haditshadits yang berkaitan dengan ihtikâr itu. Hadits-hadits itu adalah sebagai berikut:

Pertama, Hadits yang diriwayatkan oleh Abu Daud dari Abu bakr Ibn Abi Syaibah ${ }^{19}$

"Tidak menimbun kecuali orang yang berdosa".

Kedua, Hadits dari Nashr ibn Ali al-Jahdlam ${ }^{20}$

"Orang-orang yang menawarkan barang dan menjualnya dengan harga murah (jalib) diberi rizqi, sedangkan orang yang menimbun dilaknat.

Ketiga, Hadits dari Yahya Ibn Hakim ${ }^{21}$

"Siapa saja yang menimbun makanan orang Islam Allah Swt akan menghukumnya dengan penyakit kusta atau bangkrut."

Hadis-hadis yang penulis tampilkan itu, secara umum memberikan justifikasi negatif terhadap praktik ihtikar tersebut. Penilaian semacam itu ditandai dengan kata khâti', la'an, majzûm dan iflas. Khati' dan lainnya itu mengandung pengertian bahwa pelaku ihtikâr (muhtakir) berdosa karena perbuatannya itu bisa berakibat kesulitan bagi masyarakat dalam hal mendapatkan keperluannya. Kesulitan masyarakat untuk mendapatkan keperluannya di samping karena cadangan menipis atau bahkan tidak ada sama sekali, juga karena meskipun ada, harga sangat tinggi. Kondisi inilah yang ditunggu-tunggu oleh muhtakir guna mendapatkan keuntungan yang berlipat ganda. ${ }^{22}$ Keadaan ini menyebabkan masyarakat sulit untuk mendapatkan pangan (qût). ${ }^{23}$ Praktik ekonomi semacam ini sangat ber-

${ }^{19}$ Abû 'Abd Allâh Ibn Muhammad Ibn Yazîd al-Qazwini, Sunan Ibn Mâjah (Bairut: Darul Fikr, t.t.), h. 728. Di dalam Sahih Muslim hadits itu berbunyi, "Man ihtakara fahuwa khâti", (siapa saja yang menimbun maka ia berdosa). Lihat Sahih Muslim, jilid II, h. 52

${ }^{20}$ Abû 'Abd Allâh Ibn Muhammad Ibn Yazîd al-Qazwini, Sunan Ibn Mâjah . ., h. 728

${ }^{21}$ Abû 'Abd Allâh Ibn Muhammad Ibn Yazîd al-Qazwini, Sunan Ibn Mâjah . ., h. 728

${ }^{22}$ Taqiy al-Dîn al-Nabhani, Membangun Sistem Ekonomi Alternatif: Perspektif Islam, (Surabaya: Risalah Gusti, 1996), h. 209. Lihat juga Zaydan, h. 72, Yusuf Qurdhawi, h. 442

${ }^{23}$ Ahmad al-Riyadi, Yas'alunaka fi al-Dîn wal-Hayah, (Bairut: Daul Jail, 1990), h. 151 
tentangan dengan prinsip hukum Islam, 24 (tidak boleh berbuat yang berbahaya dan membahayakan orang lain). Karena tujuan mereka hanya semata-mata mencari keuntungan pribadi sebanyak-banyaknya dan di dalam pikiran mereka tidak pernah terlintas kesulitan yang dialami masyarakat. Apa yang mereka lakukan di dalam ihtikâr itu merupakan bentuk praktik ekonomi kapitalis yang hanya semata-mata mencari keuntungan belaka. ${ }^{25}$ Melihat perilaku mereka yang tidak Islami dan manusiawi itu, Nabi memberikan gelar negatif itu kepada mereka. Oleh sebab itu, ulama berpendapat bahwa ihtikâr itu pada prinsipnya haram, karena merusak kestabilan harga di pasar. ${ }^{26}$ Meskipun demikian, tidak semua ikhtiar diharamkan. Hal ini, terlihat dari kata جالب di dalam hadits nabi di atas, جالب pada dasarnya juga mengandung arti menimbun sebagaimana Lحتكر Letak perbedaan pada kedua pedagang tersebut adalah pada motivasi mereka masing-masing. Motivasi pada جالب adalah menimbun untuk dijadikan sebagai cadangan guna menghadapi masa krisis dan kemudian menjualnya pada masa krisis itu dengan harga yang layak. ${ }^{27}$ Sehubungan dengan hal itu perlu diperhatikan kisah Umar ibn Khattab ketika melakukan inspeksi pasar ketika itu. Selengkapnya terjemahan dari kisah itu adalah sebagai berikut:

Diriwayatkan bahwa Umar Ibn Khattab ra. keluar dengan para sahabatnya, maka (tiba-tiba) ia melihat tumpukan bahan makanan di pintu Mekkah. (Melihat itu) ia berkata "makanan apa ini?" Mereka menjawab "makanan ini dijual kepada kami. Umar berkata, "Allah Swt memberkati makanan itu dan orang yang menjualnya. Dikatakan kepadanya, sesungguhnya makan itu sebelumnya ditimbun. Ia berkata "Siapa yang menimbunnya?" mereka menjawab budak Usman dan budakmu. Kemudian ia mengutus seseorang untuk menanyakan hal itu kepada mereka berdua. (Setibanya utusan itu bertanya) "apa yang menyebabkan kamu menumpuk makanan orang Islam? Mereka menjawab "tidak, kami membeli dengan uang kami untuk kemudian

${ }^{24}$ Jalal al-Dîn 'Abd al-Rahmmân Ibn Abî Bakr al-Suyûthi, al-Asybah wa al-Nadhair, (Bairut: Darul-Fikr, t.t.), h. 113

${ }^{25}$ Yûsuf Qardlawi, Fatâwâ Mu'âshirah, (Kairo: Dâr al-Wafa', 1993), h. 441

${ }^{26}$ Sayid Sabiq, Fiqh al-Sunnah, (Bairut: Dâr al-Fikr, 1983), h. 162. Lihat juga Yûsuf Qardlawi, Fatâwâ Mu'âshirah.., h. 441.

${ }^{27}$ Sayid Sabiq, Fiqhus-Sunnah..., h. 165. 
menjualnya? Lantas utusan Umar tadi membacakan hadits Nabi yang artinya, "Siapa saja yang menimbun makanan orang Islam, ia tidak akan meninggal sebelum terkena penyakit kusta atau bangkrut. Tidak lama kemudian budak Usman menjualnya kecuali budak Umar. Menurut riwayat budak Umar tadi kena penyakit kusta. ${ }^{28}$

Cerita di atas menunjukkan ada dua hal yang bisa dipahami. Pertama bahwa orang yang menghimpun dan menahan makanan dengan maksud menjadikan sebagai cadangan pada masa krisis pangan dan untuk kemudian menjualnya dengan harga yang wajar, tidaklah diharamkan. Kedua bahwa apabila motivasi penimbunan itu hanya untuk menunggu harga tinggi guna mendapatkan keuntungan yang besar, sudah pasti hal ini diharamkan karena praktik itu bertentangan dengan maslahat ammah.

Sehubungan dengan hal itu, ulama memberikan kriteria tertentu terhadap bentuk ihtikâr (penimbunan) yang diharamkan. ${ }^{29}$ Kriteria itu adalah sebagai berikut: a) Barang-barang yang ditimbun hendaklah melalui proses pembelian sebelumnya dari masyarakat. Adapun apabila barang dagangan itu semata-mata dari hasil pertanian ${ }^{30}$ sendiri (seperti apa yang dilakukan Nabi Yusuf itu) tidaklah termasuk ihtikâr yang diharamkan; b) Barang-barang itu berupa makan pokok (qût);31 c) Penimbunan barang dagangan itu hendaklah menyulitkan masyarakat. Di antara yang mengindikasikan hal itu adalah apabila di dalam suatu kota terdapat muhtakir (memonopoli penguasaan barang dagangan). Di samping itu juga, penimbunan dilakukan pada masa krisis pangan yang sudah mulai terjadi. Apabila hal itu dilakukan jauh-jauh dari sebelumnya seperti apa yang dilakukan Badan Urusan Logistik (Bulog) di Indonesia, tidak termasuk

${ }^{28}$ Ibn Qudâmah, al-Mughni li Ibn Qudâmah, (Riyadl: Maktabah al-Riyâdliyah, t.t.), Jus IV, h. 243.

${ }^{29}$ Sayid Sabiq, Fiqh al-Sunnah.., 162. Lihat juga Yûsuf Qardlawi, Fatâwâ Mu'âshirah, h. 441 .

${ }^{30}$ Sayid Sabiq, Fiqh al-Sunnah.., 162.

${ }^{31}$ Ibn Qudâmah, al-Mugni..., h. 244-245, Jumhur Ulama (selain Syafi'i dan Ahmad Ibn Hanbal) berpendapat bahwa ihtikar tidak hanya terbatas pada qut saja melainkan juga termasuk semua kebutuhan masyarakat yang apabila dengan adanya ihtikar itu harga menjadi tidak stabil di pasaran. Sebagian lagi hanya membatasi kepada makan dan pakaian. Yusuf Qardlawi, h. 431-442. Lihat juga Al-Kahlani di dalam Subulus Salam, hlm 25-26. 
di dalam bentuk ihtikâryang diharamkan, karena hal itu bisa memberikan manfaat di kala krisis pangan terjadi. ${ }^{32}$

Untuk menghidari terjadinya ihtikâr, salah satu cara yang harus ditempuh adalah mencegah praktik monopoli ${ }^{33}$ di dalam pengelolaan barang-barang dagangan. Praktik semacam itu harus dicegah guna menghindari madlarat yang besar bagi masyarakat. Tindakan ini sangat sesuai dengan prinsip شد الذريعة di dalam Islam. Untuk merealisasikan hal itu peran serta pemerintah sangat besar mengingat ia mempunyai kekuasaan (otoritas). Dengan otoritasnya itu ia berhak mengatur dan mencegah praktik ihtikar dan monopoli agar oصحة العامة bisa terlindingi, meskipun di dalam melindungi مصلحة العامة tadi, مصلحة الفردية (individu) harus dikorbankan. ${ }^{34}$ Salah satu bukti bagi legalisasi intervensi pemerintah di dalam mengendalikan pasar adalah hadis-hadis Nabi tersebut dan tindakan Umar Ibn Khattab. ${ }^{35}$

\section{Penutup}

Dalam rangka lebih menguatkan peran pemerintah di dalam melakukan pengawasan pasar, pemerintah berhak dan harus menentukan kriteria hukuman berupa ta'zîr. ${ }^{36}$ Bentuk hukuman itu diperlukan agar kebijakan bisa berjalan secara tegas dan lancar. Dengan demikian dapat dimengerti mengapa pembatasan pemilikan barang dagangan sangat diperlukan mengingat masalah itu akan berakibat fatal terhadap kemaslahan umat manusia pada umumnya dan masyarakat Islam pada khususnya.

Hal demikian menunjukkan bahwa, partisipasi pemerintah di dalam mencegah terjadinya praktik ihtikârdan monopoli sebagaimana disebutkan di atas, sangat diperlukan agar kemaslahatan umum dapat dilindungi.

${ }^{32}$ Ibn Qudâmah, Al-Mughni..., h. 244-245

${ }^{33}$ Ibn Qudâmah, Al-Mughni..., h. 245

${ }^{34}$ Muhammad Abû Zahrah, Ushul al-Fiqh, (t.tp: Dar al-Fikr al-'Arabi, t.t.), h. 377. Lihat juga Abdul Wahhab Khallaf, di dalam Ilm Usul al-Fiqh, h. 208

${ }^{35}$ Ibn Qudâmah, Al-Mughni..., h. 244. Lihat juga Imam Malik di dalam Al-Muwatta', h. 421. Irfan Mahmud Ra'ana, h. 57

36 Ta'zir adalah suatu bentuk hukum yang semata-mata pertimbangan hakim (penguasa) menurut syaltut, segala bentuk hukum yang tidak dijelaskan masih disebut ta'zir. Mahmûd Syaltût, Al-Islam, Aqîdah wa Syarîah, (Mesir: Darul Qalam, 1986), h. 316-317 


\section{Pustaka Acuan}

Ali, H.A. Mukti, "Agama dan Perkembangan Ekonomi di Indonesia", Dalam Muhammad Wahyuni Nafis dkk, (Ed), Kontekstualisasi Ajaran Islam: 70 tahun Prof. Dr. Munawir Sjadzalie, M.A. Jakarta: Paramadina, 1995, Cetakan ke-1.

Azdi al-, Abû Daud Sulaiman Ibn al-Asy'ari al-Sajistani, Sunan Abû Daud, Bairut: Dar al-Fikr, t.t., Jilid II.

Bedjaouni, Muhammad, Menuju Tata Ekonomi Dunia Baru, Jakarta: Sumber Bahagia, 1985,

Bukhari al-, Abû 'Abd Allâh Muhammad Ibn Ismâil Ibn Ibrahim Ibn alMu'asyarah Ibn Birdazbah, Sahih al Bukhari, Kairo: Mathabi'uay Sya'bi, t.t.

Ibn Qudâmah, al-Mughni li Ibn Qudâmah, Riyadh: Maktabah alRiyâdliyah, t.t·

Nabhani al-, Taqiy al-Dîn, Membangun Sistem Ekonomi Alternatif: Perspektif Islam, Surabaya: Risalah Gusti, 1996.

Qardlawi, Yûsuf, Fatâwâ Mu'âshirah, Kairo: Dâr al-Wafa', 1993.

Qazwini al-, Abû 'Abd Allâh Ibn Muhammad Ibn Yazîd, Sunan Ibn Mâjah (Bairut: Darul Fikr, t.t.),

Rahardjo, M. Dawam, Ensiklopendi Al-Qur'an, Jakarta: Paramadina, 1996, Cetakan 1.

Rahardjo, M. Dawam, Perspektif Deklarasi Makkah Menuju Ekonomi Islam, Bandung: Mizan, 1987, Cetakan ke-1.

Riyadi al-, Ahmad, Yas'alunaka fi al-Dîn wal-Hayah, Bairut: Daul Jail, 1990.

Sayid Sabiq, Fiqh al-Sunnah, Bairut: Dâr al-Fikr, 1983.

Soebadio, Haryati, Bahan Kuliah Metodologi Penelitian Sosial Budaya, Pascasarjana IAIN Jakarta, Bagian II.

Suyûthi al-, Jalal al-Dîn 'Abd al-Rahmân Ibn Abî Bakr, al-Asybah wa alNadhair, Bairut: Darul-Fikr, t.t.) 
Syaltut, Mahmûd, Al-Islam, Aqidah wa Syari'ah, Mesir: Dar a- Qalam, 1986. Syuaib, Joesoef, Masalah Zakat dan Sistem Moneter, Medan: Rainbow, 1987, cetakan I.

Yafi, Ali, Menggagas Fikih Sosial, Bandung: Mizan, 1994.

Zaydan, Abdul Karim, al-Fard wa al-Daulah, Lebanon: Darul Qur'an alKarim, 1978. 